\title{
A Phase I study evaluating the effect of age and weight on the pharmacokinetics of an injectable formulation of diclofenac solubilized with hydroxypropyl- $\beta$-cyclodextrin
}

\author{
This article was published in the following Dove Press journal: \\ Clinical Pharmacology:Advances and Applications \\ 15 December 2016 \\ Number of times this article has been viewed
}

\author{
Ronald Goldwater' \\ William G Kramer ${ }^{2}$ \\ Douglas A Hamilton ${ }^{3,4}$ \\ Eric Lang ${ }^{4,5}$ \\ Jianyuan Wang ${ }^{4}$ \\ Donna E Madden ${ }^{4}$ \\ Peter G Lacouture ${ }^{6,7}$ \\ Atulkumar Ramaiya ${ }^{8}$ \\ Daniel B Carr 4 ,9 \\ 'PAREXEL International, Baltimore, \\ MD, ${ }^{2}$ Kramer Consulting, LLC, \\ North Potomac, MD, ${ }^{3} \mathrm{New}$ Biology \\ Ventures, LLC, San Mateo, CA, ${ }^{4}$ Javelin \\ Pharmaceuticals, Cambridge, MA \\ (now Hospira, a Pfizer company, Lake \\ Forest, IL, USA), ${ }^{5}$ Covance, Princeton, \\ NJ, ${ }^{6}$ Magidom Discovery, LLC, \\ Lindenhurst, IL, ${ }^{7}$ Brown University \\ School of Medicine, Providence, RI, \\ ${ }^{8}$ Global Medical Affairs, Hospira, \\ a Pfizer company, Lake Forest, IL, \\ ${ }^{9}$ Department of Anesthesiology, Tufts \\ Medical Center, Boston, MA, USA
}

Correspondence: Daniel B Carr Department of Anesthesiology, Tufts Medical Center, \#298, 800 Washington Street, Boston, MA 02III, USA.

$\mathrm{Tel}+\mathrm{I} 6176369710$

Fax +l 6176369709

Email daniel.carr@tufts.edu
Purpose: The analgesic and opioid-sparing effects of nonsteroidal anti-inflammatory drugs can be beneficial in postoperative populations. Hydroxypropyl- $\beta$-cyclodextrin (HP $\beta C D)$-diclofenac is an injectable formulation of diclofenac solubilized with HP $\beta C D$ that is administered as a low-volume intravenous bolus. This open-label, single-dose study examined the effects of age and weight on the pharmacokinetic (PK) profile of HP $\beta C D$-diclofenac.

Methods: Eighty-eight adult volunteers were enrolled. An age-based cohort included 34 subjects 55-82 years old stratified into three groups and receiving HP $\beta C D$-diclofenac $18.75 \mathrm{mg}$. A weight-based cohort included 54 subjects stratified into five groups based on body weight and body mass index and receiving HPßCD-diclofenac $37.5 \mathrm{mg}$. PK analysis was performed on blood samples collected predosing and at predefined intervals (5, 10, 20, 30, and 45 minutes; 1 , $1.5,2,2.5,3,4,6,8,10,12$, and 18 hours) postdosing. Diclofenac PK parameters were examined in the individual cohorts, and regression analyses of the relationship between age, weight, and PK parameters were performed on pooled data from all enrolled subjects.

Results: Examination of the age-based cohort revealed similar diclofenac PK parameters across age groups. PK parameters were likewise similar across weight groups in the weight-based cohort. Regression analysis on pooled data from the age- and weight-based cohorts revealed that increasing body weight was associated with a significant increase in diclofenac clearance (CL), suggesting decreased exposure in high-weight patients. Analysis of the pooled population also demonstrated an inverse relationship between age and elimination half-life $\left(t_{1 / 2}\right)$, likely due to a decrease in the volume of distribution $\left(V_{\mathrm{z}}\right)$ with increased age, not a change in CL. There were no deaths, serious adverse events, or adverse events that led to discontinuation.

Conclusion: This study suggests that the CL of diclofenac is not dependent on age in elderly subjects receiving HP $\beta C D$-diclofenac but indicates that diclofenac CL increases with increasing body weight.

Keywords: analgesia, pain control, pharmacokinetics, obesity, elderly, NSAID

\section{Introduction}

Nonsteroidal anti-inflammatory drugs (NSAIDs) are an integral part of multimodal postoperative analgesic regimens, which rely on combinations of medications from different analgesic classes to provide pain relief while limiting adverse effects associated with individual classes. ${ }^{1,2}$ There are, however, relatively few available options in the United States for fast-acting injectable NSAIDs that are appropriate for management 
of postoperative pain. Furthermore, NSAIDs can present risks of serious complications and are thus either not used in certain populations or require dose adjustments that can limit their efficacy. ${ }^{3}$

Surgeries in high-risk populations present a challenge for appropriate pain management. One such high-risk population is the elderly, who represent an increasing proportion of the general population, are increasingly likely to undergo major surgery, ${ }^{4}$ and are more likely to have comorbidities and suffer complications of surgery. ${ }^{5}$ In addition, age-related changes in drug metabolism may cause changes in drug half-life or sensitivity, and susceptibility to the side effects of opioid analgesics, such as delirium, sedation, and obstructive apnea, may be increased in the elderly. ${ }^{4}$ Overweight patients also represent a substantial segment of the population, with the proportion of US adults who are obese estimated to exceed $35 \% .{ }^{6}$ With respect to postoperative pain management, obese patients are particularly susceptible to changes in drug disposition, which may require increases or decreases in dosing paradigms to maximize efficacy and minimize safety concerns. Exacerbation of postsurgical respiratory complications related to obstructive sleep apnea that are common in obese populations can arise with opioid use, ${ }^{7}$ and guidelines for postoperative pain management in obese patients emphasize the use of local anesthetics and NSAIDs. ${ }^{8,9}$ Taken together, the requirements and challenges related to pain management in both elderly and obese populations highlight the need for improved understanding of the pharmacokinetic (PK) factors that may impact patient safety and response to analgesic therapy.

The NSAID diclofenac inhibits both cyclooxygenase (COX)-1 and COX-2 $2^{10}$ and has well-established efficacy in treating acute postoperative pain. ${ }^{11-13}$ Hydroxypropyl$\beta$-cyclodextrin (HPßCD)-diclofenac (Dyloject ${ }^{\mathrm{TM}}$, Hospira, a Pfizer company, Lake Forest, IL, USA) is an injectable formulation of diclofenac solubilized with HP $\beta C D$ that is approved for use in the United States. A previous intravenous (IV) diclofenac formulation available only outside of the United States employs propylene glycol and benzyl alcohol for solubilization and requires prolonged IV infusion times to avoid solvent-associated vascular irritation. ${ }^{14,15}$ This formulation must also be diluted and buffered with sodium bicarbonate and administered immediately following preparation. ${ }^{15}$ HP $\beta C D$-diclofenac, a stable, ready-to-use solution, minimizes the risks associated with the preparation and administration of parenteral drugs. ${ }^{16,17}$ In clinical trials, HP $\beta C D$-diclofenac has demonstrated safety and efficacy in treating pain following dental, abdominal/pelvic, and orthopedic surgery, ${ }^{18-21}$ as well as less platelet inhibition than the NSAID ketorolac and acetylsalicylic acid in healthy subjects. ${ }^{22}$ In addition, a previous study has reported the PK of diclofenac after single and multiple doses of HP $\beta C D$-diclofenac in healthy adult ( $\geq 18$ years old) volunteers. ${ }^{23}$ The objective of this study was to evaluate the PK of HP $\beta C D$-diclofenac in adult subjects based on age and weight (including adjustments for body mass index [BMI]).

\section{Methods \\ Study population}

A total of 340 individuals were screened for inclusion in the study (Figure 1). Overall, 151 individuals met the study screening criteria. Seventeen of these individuals were not enrolled given that the groups to which they were to be assigned had already been filled. In addition, 31 eligible subjects withdrew consent after screening. There were 88 total participants in the study, which was conducted at two US sites, PAREXEL Clinical Pharmacology Research in Baltimore, MD, and Comprehensive Phase One in Miramar, FL. The clinical study protocol, written informed consent forms, and any amendments requiring approval were reviewed and approved by The Chesapeake Research Review, Inc. institutional review board for both study sites. All study participants provided written informed consent to be included in the study. Subjects were assigned to one of two study cohorts, which were based on age and weight/ BMI, respectively. Subjects enrolled into the age-based cohort were required to be $\geq 55$ years of age and have body weight 45-95 kg and BMI 19-30 kg/m². Subjects enrolled into the weight-based cohort were required to be $18-55$ years of age and have body weight 40-159 $\mathrm{kg}$ and BMI $\geq 15 \mathrm{~kg} / \mathrm{m}^{2}$. All volunteers were required to be nonsmokers, healthy enough for study participation, and able to communicate with study personnel. Premenopausal female volunteers were required to have a negative pregnancy test, be nonlactating, and practicing an approved form of contraception. Subjects were excluded if they had any significant medical history or clinically relevant laboratory test results, were serologically positive for the human immunodeficiency virus, hepatitis B virus, or hepatitis $\mathrm{C}$ virus, had hypersensitivity to NSAIDs or diclofenac, or were substance abusers. Restrictions were placed on certain disease states, such as current intestinal disorders or infections, peptic ulcers, gastrointestinal bleeding, or cerebral hemorrhage, as well as specific previous surgeries, including bariatric surgery and bowel resection. Only specified concomitant medications, such as appetite suppressants or herbal medications for subjects in the weight-based cohort, resulted in exclusion from the study. Volunteers 


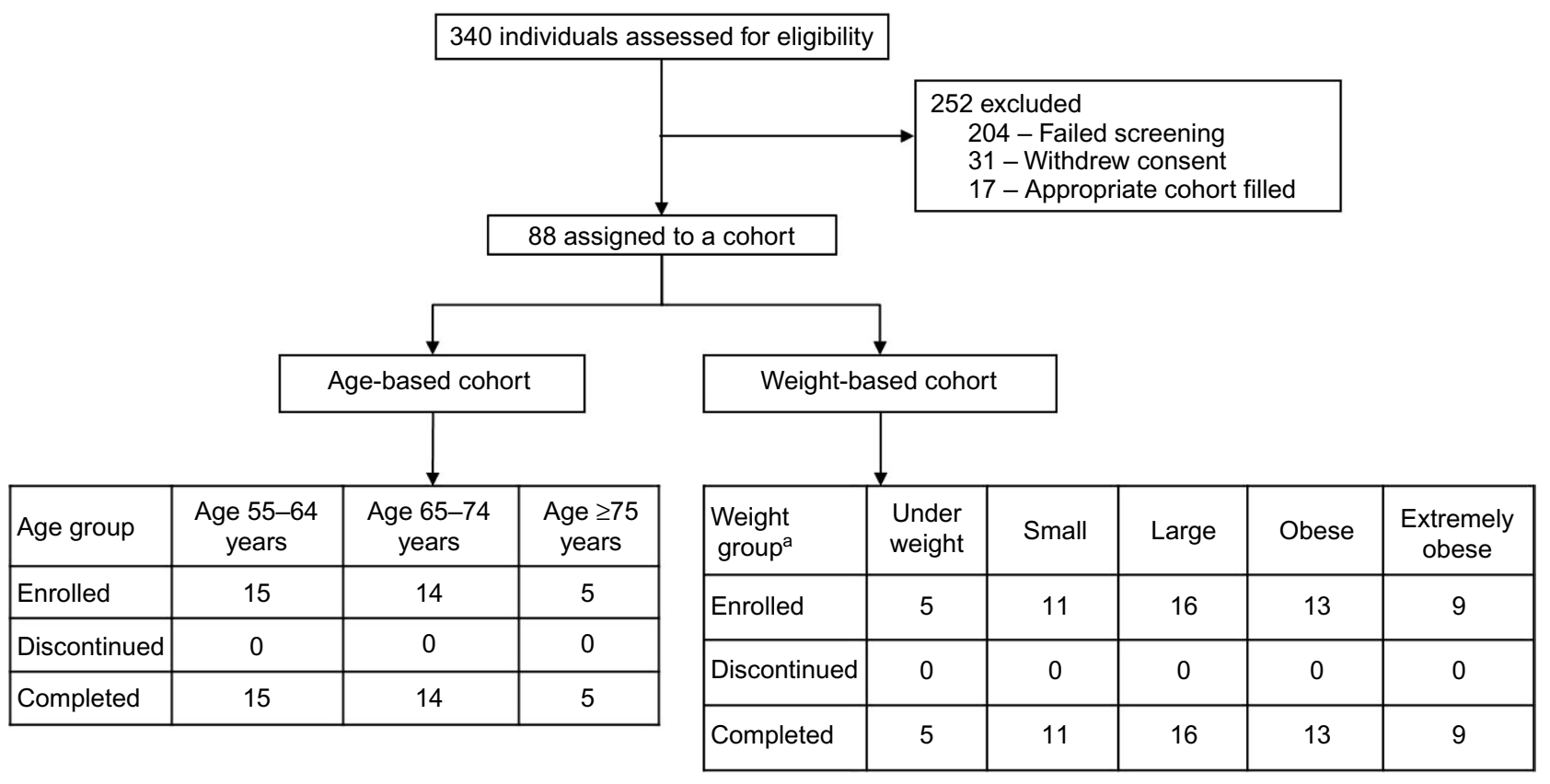

Figure I Distribution of subjects assigned to age- and weight-based cohorts.

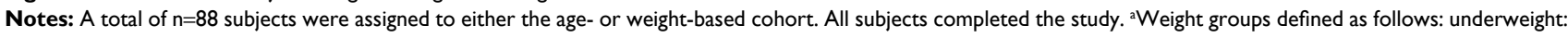
BMI I5-18.9 kg/m²; small: BMI 19-24.9 kg/m², weight $\geq 45 \mathrm{~kg}$ and $<60 \mathrm{~kg}$; large: BMI $\geq 19 \mathrm{~kg} / \mathrm{m}^{2}$ and $<30 \mathrm{~kg} / \mathrm{m}^{2}$, weight $60-100 \mathrm{~kg}$; obese: BMI $30-40 \mathrm{~kg} / \mathrm{m}^{2}$; extremely obese: $\mathrm{BMI}>40 \mathrm{~kg} / \mathrm{m}^{2}$.

Abbreviation: BMI, body mass index.

with a history of cardiovascular events, diabetes, high blood pressure, and/or hypercholesterolemia were allowed to enroll in the study, provided that the investigator judged that study participation would not put subject health at risk.

\section{Study design}

Subjects in the age-based cohort were stratified into three groups: age 55-64 years, 65-74 years, and $\geq 75$ years. Subjects in the weight-based cohort were stratified into five groups: underweight (weight not defined, BMI $15-18.9 \mathrm{~kg} / \mathrm{m}^{2}$ ), small (weight $\geq 45 \mathrm{~kg}$ and $<60 \mathrm{~kg}$, BMI 19-24.9 $\mathrm{kg} / \mathrm{m}^{2}$ ), large (weight $60-100 \mathrm{~kg}, \mathrm{BMI} \geq 19 \mathrm{~kg} / \mathrm{m}^{2}$ and $<30 \mathrm{~kg} / \mathrm{m}^{2}$ ), obese (weight not defined, BMI $30-40 \mathrm{~kg} / \mathrm{m}^{2}$ ), and extremely obese (weight not defined, BMI $>40 \mathrm{~kg} / \mathrm{m}^{2}$; Figure 1). In addition to the $\mathrm{PK}$ analyses carried out in the defined age- and weight-based patient cohorts, data from all subjects were combined and regression analyses were performed to examine the effect of age, weight, and BMI on the independent $\mathrm{PK}$ parameters total plasma clearance (CL) and volume of distribution $\left(V_{\mathrm{z}}\right)$ and the dependent PK parameter elimination half-life $\left(t_{1 / 2}\right)$ in the pooled subject population.

Subjects were fasted overnight before a single dose of IV HP $\beta C D$-diclofenac was administered the following morning. Subjects received a standard light breakfast approximately 2.5 hours after dosing, followed by lunch and dinner approximately 4 and 10 hours after dosing, respectively. On the basis of the results of a previous PK and bioavailability study and postoperative efficacy studies, ${ }^{18,20,23}$ subjects in the weightbased cohort received an IV bolus of HP $\beta C D$-diclofenac $37.5 \mathrm{mg}$. Subjects in the age-based cohort received an IV bolus of HP $\beta C D$-diclofenac $18.75 \mathrm{mg}$. A conservative dosing methodology was chosen given that this was the first clinical study in which subjects $\geq 65$ years of age were administered HP $\beta C D$-diclofenac, and in line with typical recommendations for reduced NSAID dosage in elderly patients. ${ }^{4}$

Blood samples for PK analysis were obtained via an indwelling IV cannula or by direct venipuncture at the following time points: Time 0 (predosing), 5, 10, 20, 30, and 45 minutes and $1,1.5,2,2.5,3,4,6,8,10,12$, and 18 hours postdosing. For samples from an indwelling catheter, the first 2 $\mathrm{mL}$ of blood were drawn into a separate syringe and discarded to clear saline diluent in tubing dead space, and the last $3 \mathrm{~mL}$ were collected for analysis. Blood was collected for analysis in prelabeled $3 \mathrm{~mL}$ Vacutainer ${ }^{\circledR}$ tubes (Becton Dickinson, Franklin Lakes, NJ, USA) containing di-potassium ethylenediaminetetraacetic acid $\left(\mathrm{K}_{2}\right.$-EDTA) as an anticoagulant.

\section{PK and statistical analysis}

Plasma diclofenac concentrations were measured using a validated liquid chromatography-tandem mass spectrometry method (range: 5-2,000 ng/mL; lower limit of quantitation $(\mathrm{LOQ})=5 \mathrm{ng} / \mathrm{mL})$ performed by CEDRA Clinical Research, 
LLC (Austin, TX, USA). One subject in the weight-based cohort and six subjects in the age-based cohort had plasma diclofenac concentrations that were considered aberrant. Two subjects had concentrations at 5 minutes postdrug injection that were 8- and 30-fold higher, respectively, than the mean concentration at that time point excluding those subjects. The aberrant concentrations in the other five subjects essentially occurred during the elimination phase, ranging from 10.5- to 934-fold concentration increases from the preceding samples in these subjects. PK analyses were performed both including and excluding these subjects. The overall conclusions of the study and relationship between diclofenac CL, $t_{1 / 2}$, $V_{\mathrm{z}}$, and age or weight did not change as a result of including subjects with apparent aberrant plasma concentrations. The PK results presented here have excluded these subjects. The safety population included all subjects who received the study drug. Safety was assessed during the study by monitoring adverse events (AEs), concomitant medications, vital signs, laboratory results, and electrocardiogram and physical examination results.

PK parameters were calculated using noncompartmental analysis. Only plasma concentrations equal to or greater than the LOQ were used in the analysis. Actual sampling times were used in all PK analyses. Per protocol times were used to calculate mean plasma concentrations for graphical displays. The maximum plasma concentration $\left(C_{\max }\right)$ and time to $C_{\max }$ $\left(T_{\max }\right)$ were taken directly from the data. The elimination rate constant, $\lambda_{z}$, was calculated as the negative of the slope of the terminal log-linear segment of the plasma concentration-time curve. The range of data used for each subject and treatment was determined by visual inspection of a semilogarithmic plot of concentration vs time. $t_{1 / 2}$ was calculated according to the equation $t_{1 / 2}=0.693 / \lambda_{\mathrm{z}}$. The area under the curve (AUC) from zero to the final sample with a concentration $\geq$ LOQ $\left(\mathrm{AUC}_{(0-\mathrm{t})}\right)$ was calculated using the linear trapezoidal method and extrapolated to infinity using $\mathrm{AUC} \infty=\mathrm{AUC}_{(0-\mathrm{t})}+$ $\mathrm{CTF} / \lambda_{\mathrm{z}}$, where $\mathrm{CTF}$ is the final concentration $\geq \mathrm{LOQ}$. CL was calculated as dose/AUC, and $V_{\mathrm{z}}$ was calculated as dose $/\left(\lambda_{\mathrm{z}} \times\right.$ AUC). All PK calculations and plasma concentration vs time graphs were prepared using $\mathrm{SAS} \AA$ for Windows ${ }^{\circledR}$ Version 9.1.3 (SAS Institute Inc., Cary, NC, USA). Data for continuous PK parameters in the cohort analyses are presented as mean \pm standard deviation. For linear regression analysis of PK parameters in relation to age, weight, and BMI, statistical significance was assessed via one-way analysis of variance, with $P<0.05$ defined as statistically significant.

\section{Results}

\section{PK: cohort analyses}

All 88 subjects enrolled in the age- and weight-based cohorts completed the study. The demographic characteristics of the study population are summarized in Table 1. In total, there were 36 male subjects and 52 female subjects enrolled. PK analysis in the subjects in the age-based cohort showed no effect of age (in subjects aged 55-82 years) on the exposure of IV HP $\beta C D$-diclofenac. Mean plasma diclofenac concentration-time curves were similar for the three age groups examined (Figure 2A), and overall, mean diclofenac PK parameter values were similar between groups (Table 2). Data from patients $\geq 75$ years old suggest possible increases in $t_{1 / 2}$ and $V_{\mathrm{z}}$, as well as a possible decrease in $\lambda_{\mathrm{z}}$, compared to the other two age groups in the cohort; however, the low number of subjects in this group $(n=3)$ limits the conclusions that can be drawn. Similar to results from the age-based cohort, mean plasma diclofenac concentration-time curves were essentially the same for the five groups in the weightbased cohort (Figure 2B). Mean diclofenac PK parameter values were also similar across groups in the weight-based cohort, although there was a general trend toward increased $\mathrm{CL}$ and $V_{\mathrm{z}}$ in higher weight groups (Table 3 ).

Table I Demographic characteristics of study subjects

\begin{tabular}{|c|c|c|c|c|c|c|c|c|}
\hline Cohort (n) & $\begin{array}{l}\text { HPßCD- } \\
\text { diclofenac } \\
\text { dose, } \mathrm{mg}\end{array}$ & $\begin{array}{l}\text { Age range, } \\
\text { years }\end{array}$ & Group $(n)^{a}$ & $\begin{array}{l}\text { Mean age, } \\
\text { years (SD) }\end{array}$ & $\begin{array}{l}\text { Mean weight, } \\
\text { kg (SD) }\end{array}$ & $\begin{array}{l}\text { Mean BMI, } \\
\mathrm{kg} / \mathrm{m}^{2} \text { (SD) }\end{array}$ & $\begin{array}{l}\text { Sex, male/ } \\
\text { female, } n\end{array}$ & $\begin{array}{l}\text { Race, Black or } \\
\text { African American/ } \\
\text { White, } \mathbf{n}\end{array}$ \\
\hline \multirow[t]{3}{*}{ Age based (34) } & 18.75 & $55-82$ & $55-64$ years $(15)$ & $57.6(2.5)$ & $68.65(9.77)$ & $25.95(2.80)$ & $|3 / 2|$ & $3 / 31$ \\
\hline & & & $65-74$ years $(14)$ & $68.4(2.8)$ & $67.01(8.93)$ & $26.32(2.42)$ & & \\
\hline & & & Age $\geq 75$ years $(5)$ & $78.0(3.1)$ & $72.20(6.42)$ & $27.78(1.77)$ & & \\
\hline Weight based & 37.5 & $18-54$ & Underweight (5) & $28.0(8.0)$ & $52.00(7.16)$ & $18.00(0.63)$ & $23 / 31$ & $33 / 21$ \\
\hline \multirow[t]{4}{*}{$(54)$} & & & Small (II) & $32.5(11.1)$ & $54.27(3.79)$ & $21.19(1.77)$ & & \\
\hline & & & Large (16) & $34.5(12.5)$ & $81.53(10.29)$ & $27.08(2.01)$ & & \\
\hline & & & Obese (13) & $36.9(9.2)$ & $99.14(11.13)$ & $34.21(2.37)$ & & \\
\hline & & & Extremely obese (9) & $38.7(8.4)$ & I $26.82(20.64)$ & $43.66(2.47)$ & & \\
\hline
\end{tabular}

Notes: ${ }^{a}$ Weight groups defined as follows: underweight: BMI I5-18.9 kg/m²; small: BMI I9-24.9 kg/m², weight $\geq 45 \mathrm{~kg}$ and $<60 \mathrm{~kg}$; large: BMI $\geq 19 \mathrm{~kg} / \mathrm{m}^{2}$ and $<30 \mathrm{~kg} / \mathrm{m}^{2}$, weight $60-100 \mathrm{~kg}$; obese: BMI $30-40 \mathrm{~kg} / \mathrm{m}^{2}$; extremely obese: BMI $>40 \mathrm{~kg} / \mathrm{m}^{2}$.

Abbreviations: HP $\beta C D$, hydroxypropyl- $\beta$-cyclodextrin; BMI, body mass index; SD, standard deviation. 

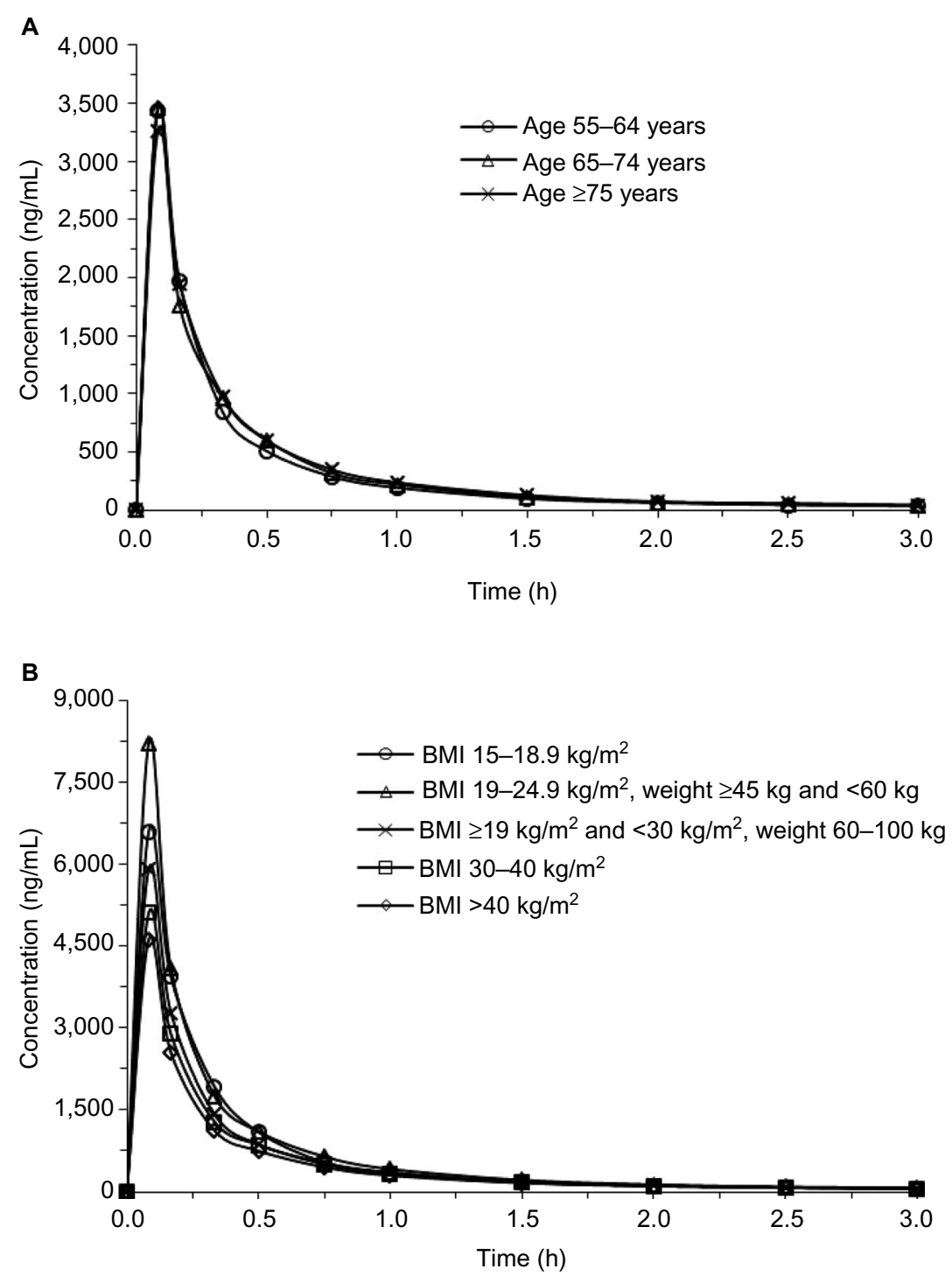

Figure 2 The effect of age and weight on diclofenac plasma concentration.

Notes: (A) Mean plasma diclofenac concentration over time following IV administration of HPßCD-diclofenac $18.75 \mathrm{mg}$ to subjects in the age-based cohort (age range: 55-82 years). (B) Mean plasma diclofenac concentration over time following IV administration of HP $\beta C D$-diclofenac $37.5 \mathrm{mg}$ to patients in the weight-based cohort. Abbreviations: BMI, body mass index; HPßCD, hydroxypropyl- $\beta$-cyclodextrin; IV, intravenous.

Table 2 PK parameters of HP $\beta C D$-diclofenac in the age-based cohort ( $n=28$ subjects; excludes subjects with aberrant plasma diclofenac measurements)

\begin{tabular}{|c|c|c|c|}
\hline \multirow[t]{2}{*}{ Parameter $^{a}$} & \multicolumn{3}{|l|}{ Age group } \\
\hline & Age $55-64$ years $(n=12)$ & Age $65-74$ years $(n=13)$ & Age $\geq 75$ years $(n=3)$ \\
\hline$C_{\max }(\mathrm{ng} / \mathrm{mL})$ & $3,439 \pm 855(12)$ & $3,465 \pm 738(13)$ & $3,257 \pm 750$ \\
\hline$T_{\max }(\mathrm{h})$ & $0.083(12)$ & $0.083(13)$ & $0.083(3)$ \\
\hline $\mathrm{AUC}_{(0-t)}(\mathrm{h} \times \mathrm{ng} / \mathrm{mL})$ & $\mathrm{I}, 087 \pm 288(\mathrm{I})$ & $\mathrm{I}, \mathrm{I} 43 \pm 26 \mathrm{I}(\mathrm{I})$ & $1,200 \pm 95.9(3)$ \\
\hline $\mathrm{AUC}_{\infty}(\mathrm{h} \times \mathrm{ng} / \mathrm{mL})$ & $1,126 \pm 291(11)$ & $\mathrm{I}, \mathrm{I} 78 \pm 263(12)$ & $1,220 \pm 96.8(3)$ \\
\hline$t_{1 / 2}(\mathrm{~h})$ & $1.39 \pm 0.43(11)$ & $1.42 \pm 0.34(12)$ & $2.14 \pm 0.61$ \\
\hline$\lambda_{\mathrm{z}}\left(\mathrm{h}^{-1}\right)$ & $0.5437 \pm 0.1728(\mathrm{II})$ & $0.5165 \pm 0.135 I(12)$ & $0.3438 \pm 0.1035(3)$ \\
\hline $\mathrm{CL}(\mathrm{mL} / \mathrm{min})$ & $274 \pm 70.6(11)$ & $257 \pm 52.2(12)$ & $239 \pm 19.8(3)$ \\
\hline$V_{z}(\mathrm{~L})$ & $32.7 \pm 13.3(1 \mathrm{I})$ & $31.5 \pm 9.26(12)$ & $44.3 \pm 13.1$ (3) \\
\hline
\end{tabular}

Notes: aReported as arithmetic mean \pm standard deviation (n), except for $T_{\max }$ for which the median (n) is reported.

Abbreviations: $C_{\max }$, maximum observed plasma concentration; $T_{\max }$, time at which $C_{\max }$ is observed; AUC, area under the curve; $A \cup C_{(0-t)}, A \cup C$ up to the last quantifiable concentration; $A \cup C \infty$, AUC from time zero to infinite time; $t_{1 / 2}$, apparent elimination half-life; $\lambda_{z}$, terminal elimination rate constant; $C L$, clearance; $V_{z}$, volume of distribution; HP $\beta C D$, hydroxypropyl- $\beta$-cyclodextrin; PK, pharmacokinetics. 
Table 3 PK parameters of HP $\beta C D$-diclofenac in the weight-based cohort ( $n=53$ subjects; excludes subjects with aberrant plasma diclofenac measurements)

\begin{tabular}{|c|c|c|c|c|c|}
\hline \multirow[t]{2}{*}{ Parameter $^{a}$} & \multicolumn{5}{|l|}{ Weight group } \\
\hline & $\begin{array}{l}\text { BMI I5- } 18.9 \mathrm{~kg} / \mathrm{m}^{2} \\
(\mathrm{n}=5)\end{array}$ & $\begin{array}{l}\text { BMI I9-24.9 kg/m } \\
\text { Weight } \geq 45 \mathrm{~kg} \text { and } \\
<60 \mathrm{~kg}(\mathrm{n}=\mathrm{II})\end{array}$ & $\begin{array}{l}\text { BMI } \geq 19 \mathrm{~kg} / \mathrm{m}^{2} \text { and } \\
<30 \mathrm{~kg} / \mathrm{m}^{2} \\
\text { Weight } 60-100 \mathrm{~kg}(\mathrm{n}=16)\end{array}$ & $\begin{array}{l}\text { BMI } 30-40 \mathrm{~kg} / \mathrm{m}^{2} \\
(n=13)\end{array}$ & $\begin{array}{l}\text { BMI }>40 \mathrm{~kg} / \mathrm{m}^{2} \\
(\mathrm{n}=8)\end{array}$ \\
\hline$C_{\max }(\mathrm{ng} / \mathrm{mL})$ & $6,594 \pm 2,258(5)$ & $8,212 \pm I, 952(I I)$ & $5,903 \pm 1,060(16)$ & $5,103 \pm 0,672(13)$ & $4,616 \pm 1,639(8)$ \\
\hline$T_{\max }(\mathrm{h})$ & $0.083(5)$ & $0.083(\mathrm{II})$ & $0.083(16)$ & $0.083(13)$ & $0.083(8)$ \\
\hline $\mathrm{AUC}_{(0-t)}(\mathrm{h} \times \mathrm{ng} / \mathrm{mL})$ & $2,190 \pm 609(5)$ & $2,413 \pm 616(I I)$ & $|, 9| 6 \pm 4 \mid I(16)$ & $1,740 \pm 265(13)$ & $1,569 \pm 316(8)$ \\
\hline $\mathrm{AUC}_{\infty}(\mathrm{h} \times \mathrm{ng} / \mathrm{mL})$ & $2,103 \pm 65 \mid(4)$ & $2,429 \pm 616(\mathrm{II})$ & $1,933 \pm 412(16)$ & $\mathrm{I}, 757 \pm 266(13)$ & $1,640 \pm 302(7)$ \\
\hline$t_{1 / 2}(\mathrm{~h})$ & $2.03 \pm 0.47(4)$ & $\mathrm{I} .67 \pm 0.34(\mathrm{II})$ & $1.79 \pm 0.44(16)$ & $1.56 \pm 0.25(13)$ & $\mathrm{I} .8 \mathrm{I} \pm 0.57(7)$ \\
\hline$\lambda_{z}\left(h^{-1}\right)$ & $0.3593 \pm 0.1011$ & $0.432 \mathrm{I} \pm 0.0962(\mathrm{II})$ & $0.4095 \pm 0.0997(16)$ & $0.4568 \pm 0.0847(13)$ & $0.4205 \pm 0.1437(7)$ \\
\hline $\mathrm{CL}(\mathrm{mL} / \mathrm{min})$ & $297 \pm 92.4(4)$ & $255 \pm 71.4(11)$ & $314 \pm 69.3(16)$ & $338 \pm 53.0(13)$ & $363 \pm 56.0(7)$ \\
\hline$V_{z}(L)$ & $50.4 \pm 14.0$ & $36.1 \pm 10.1(\mathrm{II})$ & $47.9 \pm 13.6(16)$ & $45.5 \pm 9.60(13)$ & $56.4 \pm 19.0(7)$ \\
\hline
\end{tabular}

Notes: aReported as arithmetic mean \pm standard deviation (n), except for $T_{\max }$ for which the median (n) is reported.

Abbreviations: $C_{\max }$, maximum observed plasma concentration; $T_{\max }$, time at which $C_{\max }$ is observed; AUC ${ }_{(0-t)}$, AUC, area under the curve; AUC up to the last quantifiable concentration; $A \cup C \infty, A \cup C$ from time zero to infinite time; $t_{1 / 2}$, apparent elimination half-life; $\lambda_{z}$, terminal elimination rate constant; $C L$, clearance; $V_{z}$, volume of distribution; $\mathrm{HP} \beta C D$, hydroxypropyl- $\beta$-cyclodextrin; PK, pharmacokinetics; BMI, body mass index.

\section{PK: pooled population}

Because age and weight are continuous variables, data from the age- and weight-based cohorts were combined and regression analyses were performed on the pooled population to further investigate the relationship between age, weight, and diclofenac PK. Examination of the relationships between age and $\mathrm{CL}, V_{z}$, and $t_{1 / 2}$ for the pooled population indicated that there was a significant inverse relationship between age and $V_{\mathrm{z}}(P=0.018)$, as well as between age and $\mathrm{t}^{1} / 2(P=0.048$; Figure 3). Specifically, with increasing age, there was a significant decrease in $V_{z}$, which resulted in a significant decrease in $t_{1 / 2}$. Conversely, regression analysis of the pooled population revealed that diclofenac CL was not significantly affected by age $(P=0.18)$.

Examination of the relationships between weight and $\mathrm{CL}, V_{\mathrm{z}}$, and $t_{1 / 2}$ in the pooled population indicated that there were significant relationships between increasing weight and increasing CL, as well as weight and increasing $V_{z}$ (both $P<0.0001$; Figure 4). There was essentially no relationship between weight and $t_{1 / 2}(P=0.49)$, due to proportional increases in both CL and $V_{\mathrm{z}}$. Relationships with BMI were consistent with those for weight, a major component of BMI.

\section{Safety}

There were no deaths, no serious AEs, and no AEs that led to discontinuation from the study in either the age- or weight-based cohort. Three subjects $(8.8 \%)$ in the agebased cohort reported a total of 13 treatment-emergent AEs (Table 4). All events were considered to be mild and transient, and all but two (one incidence each of pruritus and hypertension) resolved without medical intervention. In the weight-based cohort (Table 5), $\mathrm{n}=9$ subjects (16.7\%) reported
14 treatment-emergent AEs. All AEs in the weight-based cohort were also considered to be mild and transient, and all were resolved without medical intervention. In the age-based cohort, $54.5 \%$ of AEs were considered by the investigator to be unrelated to study drug, while $57.1 \%$ of those in the weight-based cohort were considered unrelated.

\section{Discussion}

This study extends previous findings by demonstrating the PK of diclofenac based on age and weight following injection of a single dose of HP $\beta C D$-diclofenac. Analysis of diclofenac PK in all subjects demonstrated that increasing age had no effect on the total exposure of IV HP $\beta C D$-diclofenac, but did show a significant inverse relationship between age and $V_{\mathrm{z}}$, as well as age and $t_{1 / 2}$. This suggests a decreased risk of accumulation in elderly subjects. In addition, analysis of the pooled cohort demonstrated a significant increase in diclofenac $\mathrm{CL}$, and thus decreased exposure, with increasing weight. There were no deaths, no serious AEs, and no AEs that led to discontinuation from the study in any subject.

NSAID dosages are typically reduced in the elderly because this patient group can be particularly susceptible to adverse effects associated with NSAID use, such as bleeding, renal, and cardiovascular complications. ${ }^{4}$ Dosage reductions are required for IV ketorolac, for example, given that it may be cleared more slowly in the elderly and in light of the elevated sensitivity of elderly patients to dose-related adverse effects of NSAIDs, such as gastrointestinal bleeding. ${ }^{24}$ Importantly, HP $\beta C D$-diclofenac, with its balanced COX inhibition profile, may potentially pose less risk of postoperative bleeding than NSAIDs that preferentially inhibit COX-1. In a study of platelet function in human 

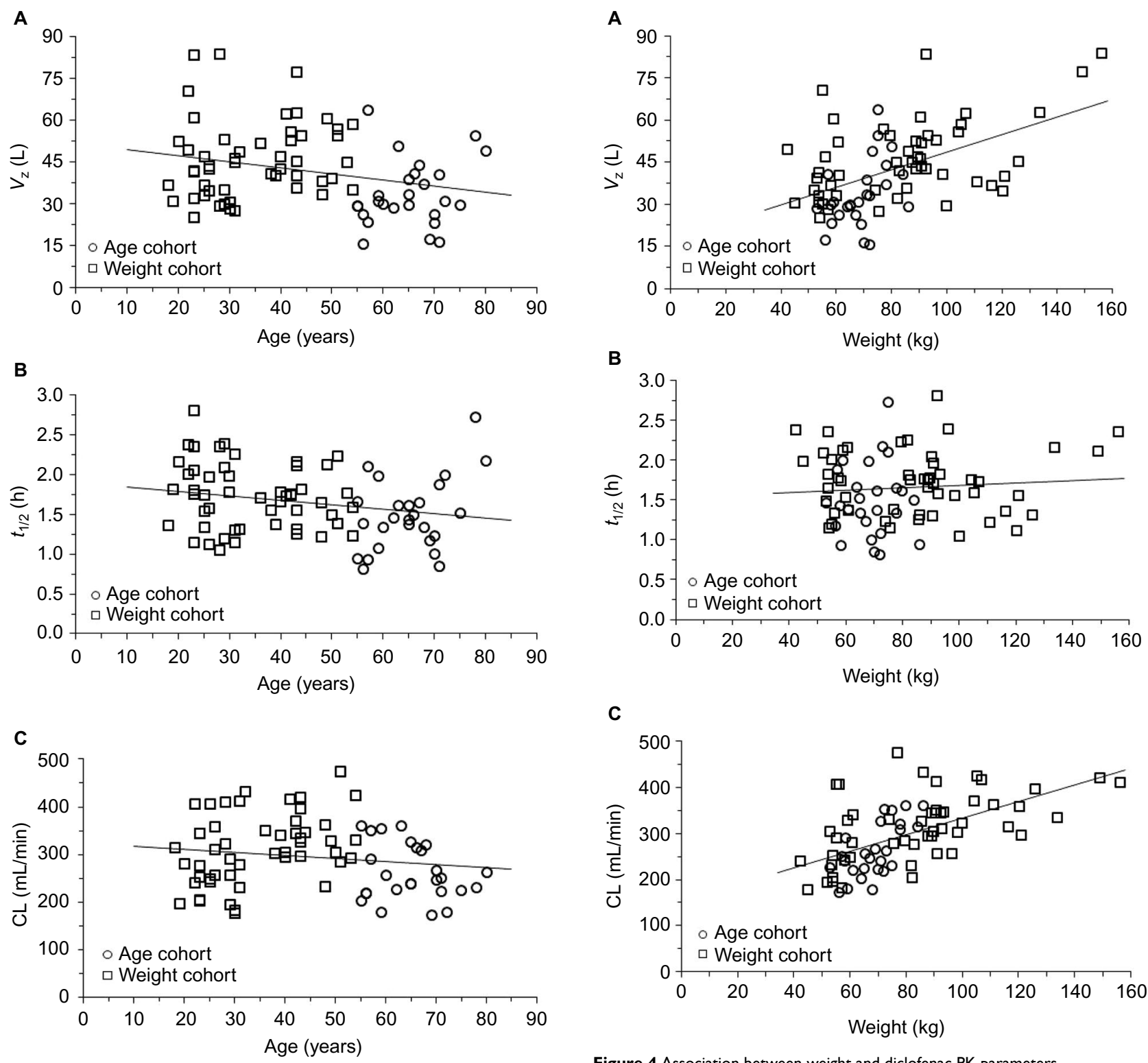

Figure 3 Association between age and diclofenac PK parameters.

Notes: Relationship between volume of distribution $\left(V_{z}\right)$; $(\mathbf{A})$, terminal elimination half-life $\left(t_{1 / 2}\right) ;(\mathbf{B})$, and $C L(C)$ and age following IV administration of HP $\beta C D$-diclofenac 18.75 or $37.5 \mathrm{mg}$. Subjects from the age- and weight-based cohorts were pooled. There was a statistically significant inverse relationship between age and $V_{z}(P=0.018)$ and $t_{1 / 2}(P=0.048)$, and a nonstatistically significant relationship between age and $C L$ $(P=0.18)$. Subjects with aberrant plasma diclofenac measurements were excluded.

Abbreviations: HP $\beta C D$, hydroxypropyl- $\beta$-cyclodextrin; PK, pharmacokinetics; $\mathrm{CL}$, clearance.

volunteers, HP $\beta C D$-diclofenac affected clotting ability to a lesser extent than ketorolac and acetylsalicylic acid. ${ }^{22}$ Also noteworthy are findings from a pivotal Phase III safety study of multiple-dose HP $\beta C D$-diclofenac in a large postoperative patient population, which demonstrated that the incidence of bleeding-related AEs was not increased in patients $\geq 65$ years old vs patients $<65$ years old. ${ }^{21}$

Consistent with existing guidelines regarding NSAID dosage in elderly patients, elderly subjects in this study were

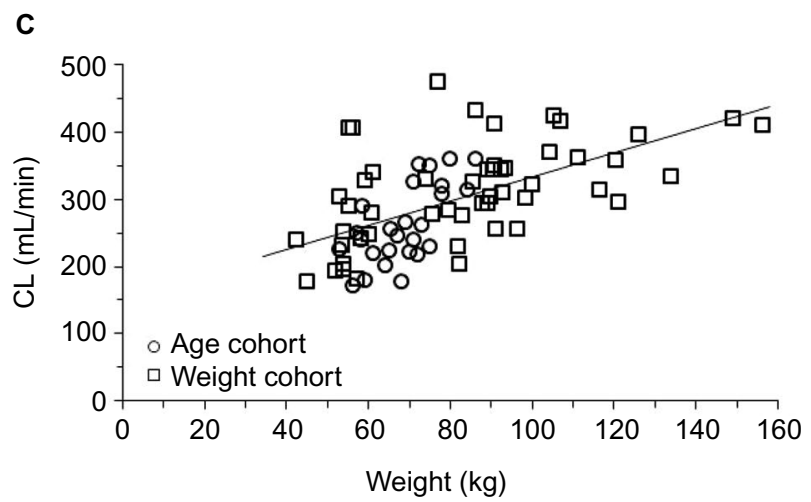

Figure 4 Association between weight and diclofenac PK parameters.

Notes: Relationship between volume of distribution $\left(V_{z}\right) ;(A)$, terminal elimination half-life $\left(t_{1 / 2}\right)$; (B), and $C L(C)$ and weight following IV administration of HPßCDdiclofenac 18.75 or $37.5 \mathrm{mg}$. Subjects from the age- and weight-based cohorts were pooled. There was a statistically significant relationship between weight and $V_{z}$ and weight and $C L$ (both $P<0.000 \mathrm{I}$ ), and a nonstatistically significant relationship between weight and $t_{1 / 2}(P=0.49)$. Subjects with aberrant plasma diclofenac measurements were excluded.

Abbreviations: $\mathrm{HP} \beta C D$, hydroxypropyl- $\beta$-cyclodextrin; $\mathrm{PK}$, pharmacokinetics; $\mathrm{CL}$, clearance.

given HP $\beta C D$-diclofenac $18.75 \mathrm{mg}$, half of the standard $37.5 \mathrm{mg}$ dose. The study results demonstrate that subject age did not affect the overall exposure of diclofenac. Age-related changes in body water and body fat, however, affect the volume of distribution $\left(V_{\mathrm{z}}\right)$ of drugs in older patients. ${ }^{4}$ In this study, pooled analysis of PK data from all subjects revealed a significant decrease in diclofenac $V_{z}$, which resulted in a significant decrease in $t_{1 / 2}$, with increased age. This suggests that there would be a decreased risk of accumulation of 
Table 4 Treatment-emergent AEs in the age-based cohort ( $n=34$ total subjects)

\begin{tabular}{|c|c|c|c|}
\hline \multirow[t]{2}{*}{ System organ class and preferred term } & \multicolumn{3}{|l|}{ Age group } \\
\hline & Age $55-64$ years $(n=15)$ & Age $65-74$ years $(n=14)$ & Age $\geq 75$ years $(n=5)$ \\
\hline Total subjects with $\geq I$ treatment-emergent $A E(\%)$ & 0 & $2(14.3)$ & I (20.0) \\
\hline GI disorders & 0 & I (7.I) & 0 \\
\hline Constipation & 0 & I (7.I) & 0 \\
\hline General disorders and administration site conditions & 0 & I (7.I) & 0 \\
\hline Injection site hematoma & 0 & $\mathrm{I}(7.1)$ & 0 \\
\hline Injection site hemorrhage & 0 & $\mathrm{I}(7.1)$ & 0 \\
\hline Injection site edema & 0 & I (7.I) & 0 \\
\hline Injection site rash & 0 & I (7.I) & 0 \\
\hline Injury, poisoning, and procedural complications & 0 & I (7.I) & 0 \\
\hline Contusion & 0 & I (7.I) & 0 \\
\hline Investigations & 0 & $\mathrm{I}(7.1)$ & 0 \\
\hline Blood amylase increased & 0 & I (7.I) & 0 \\
\hline Lipase increased & 0 & I (7.I) & 0 \\
\hline Nervous system disorders & 0 & I (7.I) & 0 \\
\hline Dizziness & 0 & I (7.I) & 0 \\
\hline Skin and subcutaneous tissue disorders & 0 & $\mathrm{I}(7.1)$ & 0 \\
\hline Erythema & 0 & I (7.I) & 0 \\
\hline Pruritus & 0 & I (7.I) & 0 \\
\hline Vascular disorders & 0 & 0 & I (20.0) \\
\hline Hypertension & 0 & 0 & I (20.0) \\
\hline
\end{tabular}

Notes: The data represents treatment-emergent AEs in the age-based cohort; number of subjects with an event (percentage of the total).

Abbreviations: AEs, adverse events; GI, gastrointestinal.

Table 5 Treatment-emergent AEs in the weight-based cohort ( $\mathrm{n}=54$ total subjects)

\begin{tabular}{|c|c|c|c|c|c|}
\hline \multirow{2}{*}{$\begin{array}{l}\text { System organ class and } \\
\text { preferred term }\end{array}$} & \multicolumn{5}{|l|}{ Weight group } \\
\hline & $\begin{array}{l}\text { BMI I5- } 18.9 \mathrm{~kg} / \mathrm{m}^{2} \\
(\mathrm{n}=5)\end{array}$ & $\begin{array}{l}\text { BMI I9-24.9 kg/m } \\
\text { Weight } \geq 45 \mathrm{~kg} \text { and } \\
<60 \mathrm{~kg}(\mathrm{n}=\mathrm{II})\end{array}$ & $\begin{array}{l}\text { BMI } \geq 19 \mathrm{~kg} / \mathrm{m}^{2} \text { and } \\
<30 \mathrm{~kg} / \mathrm{m}^{2} \\
\text { Weight } 60-100 \mathrm{~kg} \\
(\mathrm{n}=16)\end{array}$ & $\begin{array}{l}\text { BMI } 30-40 \mathrm{~kg} / \mathrm{m}^{2} \\
(n=13)\end{array}$ & $\begin{array}{l}\text { BMI >40 kg/m² } \\
(n=8)\end{array}$ \\
\hline $\begin{array}{l}\text { Total subjects with } \geq 1 \\
\text { treatment-emergent } A E(\%)\end{array}$ & 0 & $4(36.4)$ & $2(12.5)$ & $3(23.1)$ & 0 \\
\hline GI disorders & 0 & 0 & $\mathrm{I}(6.3)$ & 0 & 0 \\
\hline Diarrhea & 0 & 0 & $\mathrm{I}(6.3)$ & 0 & 0 \\
\hline Flatulence & 0 & 0 & $\mathrm{I}(6.3)$ & 0 & 0 \\
\hline $\begin{array}{l}\text { General disorders and } \\
\text { administration site conditions }\end{array}$ & 0 & $2(18.2)$ & 0 & I (7.7) & 0 \\
\hline Fatigue & 0 & I (9.I) & 0 & 0 & 0 \\
\hline Injection site hemorrhage & 0 & I (9.1) & 0 & 0 & 0 \\
\hline Injection site induration & 0 & 0 & 0 & I (7.7) & 0 \\
\hline Injection site pain & 0 & 0 & 0 & I (7.7) & 0 \\
\hline $\begin{array}{l}\text { Injury, poisoning, and procedural } \\
\text { complications }\end{array}$ & 0 & 0 & 0 & I (7.7) & 0 \\
\hline Contusion & 0 & 0 & 0 & I (7.7) & 0 \\
\hline $\begin{array}{l}\text { Musculoskeletal and connective } \\
\text { tissue disorders }\end{array}$ & 0 & I (9.1) & I (6.3) & 0 & 0 \\
\hline Arthralgia & 0 & 0 & $\mathrm{I}(6.3)$ & 0 & 0 \\
\hline Back pain & 0 & I (9.1) & 0 & 0 & 0 \\
\hline Nervous system disorders & 0 & I (9.1) & 0 & $2(15.4)$ & 0 \\
\hline Burning sensation & 0 & $\mathrm{I}(9.1)$ & 0 & 0 & 0 \\
\hline Headache & 0 & 0 & 0 & $2(15.4)$ & 0 \\
\hline Psychotic disorders & 0 & $\mathrm{I}(9.1)$ & 0 & 0 & 0 \\
\hline Euphoric mood & 0 & I (9.I) & 0 & 0 & 0 \\
\hline $\begin{array}{l}\text { Reproductive system and breast } \\
\text { disorders }\end{array}$ & 0 & I (9.1) & 0 & 0 & 0 \\
\hline Dysmenorrhea & 0 & I (9.I) & 0 & 0 & 0 \\
\hline
\end{tabular}

Notes: The data represents treatment-emergent AEs in the age-based cohort; number of subjects with an event (percentage of the total).

Abbreviations: AEs, adverse events; Gl, gastrointestinal; BMI, body mass index. 
diclofenac in elderly subjects and that HP $\beta C D$-diclofenac dose reduction in elderly patients may not be warranted. Notably, a recent study also demonstrated no accumulation of diclofenac in healthy adult volunteers following multiple HP $\beta C D$-diclofenac doses. ${ }^{23}$ Analysis of this study's age-based cohort also suggests possible increases in $t_{1 / 2}$ and $V_{\mathrm{z}}$ and a possible decrease in $\lambda_{\mathrm{z}}$ in subjects $\geq 75$ years old; however, the number of subjects in this age group in this study was limited ( $n=3)$. Thus, further PK investigation in this age group would likely be beneficial.

The results of this study also indicate an association between patient weight and diclofenac PK, as evidenced by a decrease in exposure with increasing body weight. In general, the effect of patient weight on $V_{\mathrm{z}}$ varies with the physiochemical attributes of a given drug, such as molecular size, lipid solubility, and ability to cross biological membranes. For example, the $V_{\mathrm{z}}$ for lipophilic drugs may be increased in higher weight patients due to an increased proportion of adipose tissue. ${ }^{25} \mathrm{CL}$ may also be altered in obese patients due to the presence of fatty liver disease that may affect drug metabolism. ${ }^{25}$ In this study, we observed proportional increases in both $V_{\mathrm{z}}$ and CL with increased body weight, such that the $t_{1 / 2}$ of diclofenac was not altered. Dosing adjustments for high-weight patients have been recommended for ibuprofen to achieve analgesia while maintaining the same dosing interval. ${ }^{9}$ While the PK of diclofenac following HP $\beta C D$-diclofenac administration appear to be dependent on body weight, the effect of weight on the clinical efficacy and safety of HP $\beta C D$-diclofenac has not been fully studied, and thus dose adjustments for weight based on these PK findings alone are not recommended.

\section{Conclusion}

In summary, a uniform $37.5 \mathrm{mg}$ dose of HP $\beta C D$-diclofenac for adult patients offers the benefit of simplifying treatment, reducing dosing errors, and saving time spent on dose calculations. The results of this study suggest that the CL of HP $\beta C D$-diclofenac is not altered in elderly subjects when administered at the usual dose and schedule but may be impacted by body weight.

\section{Acknowledgments}

This study was funded by Javelin Pharmaceuticals and Hospira, Inc., which was acquired by Pfizer in September 2015. The authors thank Drs Terri Lunsford and Jocelyn Swanson-Apollon of PAREXEL Clinical Pharmacology Research, and Dr William Gerson of Comprehensive Phase One, who served as study investigators. Editorial support was provided by Fred Peyerl, PhD and Scott Paluszkiewicz,
$\mathrm{PhD}$ at Boston Strategic Partners, Inc., and was funded by Hospira, which was acquired by Pfizer Inc in September 2015.

\section{Disclosure}

This study was sponsored by Javelin Pharmaceuticals, Inc., Cambridge, MA (acquired in 2010 by Hospira, Inc., Lake Forest, IL) and Hospira Inc, which was acquired by Pfizer in September 2015. The present analysis and editorial/medical writing support was funded by Hospira, a Pfizer company. DB Carr was the full-time Chief Medical Officer for the study sponsor during this trial, and served as a consultant to Hospira, Inc., following acquisition of Javelin Pharmaceutical, Inc. in 2010. DA Hamilton was a stockholder and consultant to Javelin Pharmaceuticals at the time of the study, and subsequent to Javelin's acquisition by Hospira in 2010, became a consultant to Hospira. J Wang, E Lang, and D Madden were employees of the study sponsor during the time of the trial. PG Lacouture and A Ramaiya are employees of Hospira, Inc. The authors report no other conflicts of interest in this work.

\section{References}

1. Macintyre PE, Schug SA, Scott DA, Visser EJ, Walker SM. Acute Pain Management: Scientific Evidence. 3rd ed. Melbourne, Australia: Australian and New Zealand College of Anaesthetists and Faculty of Pain Medicine; 2010.

2. American Society of Anesthesiologists Task Force on Acute Pain Management. Practice guidelines for acute pain management in the perioperative setting: an updated report by the American Society of Anesthesiologists Task Force on Acute Pain Management. Anesthesiology. 2012;116(2):248-273.

3. Frampton C, Quinlan J. Evidence for the use of non-steroidal antiinflammatory drugs for acute pain in the post anaesthesia care unit. $J$ Perioper Pract. 2009;19(12):418-423.

4. Aubrun F, Marmion F. The elderly patient and postoperative pain treatment. Best Pract Res Clin Anaesthesiol. 2007;21(1):109-127.

5. Sieber FE, Barnett SR. Preventing postoperative complications in the elderly. Anesthesiology Clin. 2011;29(1):83-97.

6. National Center for Health Statistics. Health, United States, 2011: With Special Feature on Socioeconomic Status and Health. Hyattsville, MD: National Center for Health Statistics; 2012.

7. Cullen DJ. Obstructive sleep apnea and postoperative analgesia - a potentially dangerous combination. J Clin Anesth. 2001;13(2):83-85.

8. Schumann R, Jones SB, Cooper B, et al. Update on best practice recommendations for anesthetic perioperative care and pain management in weight loss surgery, 2004-2007. Obesity (Silver Spring). 2009;17(5):889-894.

9. Schug SA, Raymann A. Postoperative pain management of the obese patient. Best Pract Res Clin Anaesthesiol. 2011;25(1):73-81.

10. Van Hecken A, Schwartz JI, Depre M, et al. Comparative inhibitory activity of rofecoxib, meloxicam, diclofenac, ibuprofen, and naproxen on COX-2 versus COX-1 in healthy volunteers. J Clin Pharmacol. 2000;40(10):1109-1120.

11. Hyrkas T, Ylipaavalniemi P, Oikarinen VJ, Paakkari I. Preoperative intravenous diclofenac for postoperative pain prevention in outpatients. Br J Oral Maxillofac Surg. 1993;31(6):351-354.

12. Hovorka J, Kallela H, Korttila K. Effect of intravenous diclofenac on pain and recovery profile after day-case laparoscopy. Eur JAnaesthesiol. 1993;10(2):105-108. 
13. Claeys MA, Camu F, Maes V. Prophylactic diclofenac infusions in major orthopedic surgery: effects on analgesia and acute phase proteins. Acta Anaesthesiol Scand. 1992;36(3):270-275.

14. Campbell WI, Watters CH. Venous sequelae following i.v. administration of diclofenac. Br J Anaesth. 1989;62(5):545-547.

15. Voltarol ${ }^{\circledR}$ Ampoules (diclofenac sodium). [Summary of product characteristics]. Surrey, UK: Novartis Pharmaceuticals UK Ltd; 2011.

16. National Patient Safety Agency United Kingdom. Promoting safer use of injectable medicines. Available from: http://www.nrls.npsa.nhs.uk/ resources/?entryid45=59812. Accessed June 1, 2015.

17. McCormack PL, Scott LJ. Diclofenac sodium injection (Dyloject): in postoperative pain. Drugs. 2008;68(1):123-130.

18. Gan TJ, Daniels SE, Singla N, Hamilton DA, Carr DB. A novel injectable formulation of diclofenac compared with intravenous ketorolac or placebo for acute moderate-to-severe pain after abdominal or pelvic surgery: a multicenter, double-blind, randomized, multiple-dose study. Anesth Analg. 2012;115(5):1212-1220.

19. Daniels S, Melson T, Hamilton DA, Lang E, Carr DB. Analgesic efficacy and safety of a novel injectable formulation of diclofenac compared with intravenous ketorolac and placebo after orthopedic surgery: a multicenter, randomized, double-blinded, multiple-dose trial. Clin J Pain. 2013; 29(8):655-663.
20. Christensen K, Daniels S, Bandy D, et al. A double-blind placebocontrolled comparison of a novel formulation of intravenous diclofenac and ketorolac for postoperative third molar extraction pain. Anesth Prog. 2011;58(2):73-81.

21. Chelly JE, Singla SK, Melson TI, Lacouture PG, Paadre S, Carr DB. Safety of a novel parenteral formulation of diclofenac after major orthopedic or abdominal/pelvic surgery in a population including anticoagulated, elderly or renally insufficient patients: an open-label, multiday, repeated dose clinical trial. Pain Med. 2013;14(5):749-761.

22. Bauer KA, Gerson W, Wright CT, et al. Platelet function following administration of a novel formulation of intravenous diclofenac sodium versus active comparators: a randomized, single dose, crossover study in healthy male volunteers J Clin Anesth. 2010;22(7):510-518.

23. Mermelstein F, Hamilton DA, Wright C, et al. Single-dose and multipledose pharmacokinetics and dose proportionality of intravenous and intramuscular HP $\beta C D$-diclofenac (Dyloject) compared with other diclofenac formulations. Pharmacotherapy. 2013;33(10):1012-1021.

24. Ketorolac tromethamine injection solution [package insert]. Lake Forest, IL: Hospira, Inc.; 2009.

25. Hanley MJ, Abernethy DR, Greenblatt DJ. Effect of obesity on the pharmacokinetics of drugs in humans. Clin Pharmacokinet. 2010;49(2): 71-87.
Clinical Pharmacology: Advances and Applications

\section{Publish your work in this journal}

Clinical Pharmacology: Advances and Applications is an international, peer-reviewed, open access journal publishing original research, reports, reviews and commentaries on all areas of drug experience in humans. The manuscript management system is completely online and includes a very quick and fair peer-review system, which is all easy to use.

\section{Dovepress}

Visit http://www.dovepress.com/testimonials.php to read real quotes from published authors. 